\title{
Ultrastructures of Colletotrichum orbiculare in Cucumber Leaves Expressing Systemic Acquired Resistance Mediated by Chlorella fusca
}

\author{
Su Jeung Kim¹, Eun Ju Ko ${ }^{2}$, Jeum Kyu Hong ${ }^{3}$, and Yong Chull Jeun ${ }^{2,4 *}$ \\ ${ }^{1}$ Biotech Center, Pohang University of Science and Technology, Pohang, Gyeongbuk 37673, Korea \\ ${ }^{2}$ College of Applied Life Science, Sustainable Agriculture Research Institute, Jeju National University, Jeju 63243, Korea \\ ${ }^{3}$ Department of Horticultural Science, Gyeongnam National University of Science and Technology (GNTech), Jinju \\ 52725, Korea \\ ${ }^{4}$ The Research Institute for Subtropical Agriculture and Biotechnology, Jeju National University, Jeju 63604, Korea
}

(Received on September 29, 2017; Revised on December 28, 2017; Accepted on December 28, 2017)

Chlorella, one single-cell green algae organism that lives autotrophically by photosynthesis, can directly suppress some plant diseases. The objective of this study was to determine whether pre-spraying with Chlorella fusca suspension could induce systemic acquired resistance (SAR) in cucumber plants against anthracnose caused by Colletotrichum orbiculare. In order to illustrate SAR induced by algae, infection structures in host cells were observed under a transmission electron microscope (TEM). Cytological changes as defense responses of host mesophyll cells such as accumulation of vesicles, formation of sheath around penetration hyphae, and thickness of cell wells adjoining with intracellular hyphae were demonstrated in cucumber leaves. Similar defense responses were also found in the plant pre-treated with DL-3-aminobutyric acid, another SAR priming agent. Images showed that defense response of host cells was scarcely observed in untreated leaf tissues. These cytological observations suggest that $C$. fusca could induce SAR against anthracnose in cucumber plants by activating defense responses of host cells.

Keywords : algae, anthracnose, DL-3-aminobutyric acid (BABA), infection structure, plant growth promoting rhizobacteria (PGPR)

\footnotetext{
*Corresponding author.

Phone) +82-64-754-3319, FAX) +82-64-754-2351

E-mail)ycjeun@jejunu.ac.kr

(c) This is an Open Access article distributed under the terms of the Creative Commons Attribution Non-Commercial License (http:// creativecommons.org/licenses/by-nc/4.0) which permits unrestricted noncommercial use, distribution, and reproduction in any medium, provided the original work is properly cited.
}

Articles can be freely viewed online at www.ppjonline.org.
Handling Associate Editor : Sang, Mee Kyung

Chlorella belongs to green algae as eukaryotic photosynthetic microorganism. Microalgae including Chlorella has been broadly used for human being for long time. In the last two decades, many studies have successfully purified wastewater using cultivated microalgae (Chiu et al., 2015). Chlorella has also been spotlighted as a candidate of renewable energy source such as biofuel due to its effective photosynthesis. It also contains abundant nutrients (Arita et al., 2015). Moreover, conversion of microalgae cultivating in wastewater to biofuel has been regarded as an additional benefit that is favorable for environment (Bhatt et al., 2014).

After the report of antifungal activity of Chlorella vulgaris (Matusiak and Krzywicka, 1975), some experiments concerning microalgae as an effective microorganism in agriculture have been carried out. As a bio-fertilizer, C. vulgaris could extend the freshness during storage of strawberry fruits or various vegetables such as lettuce, kale, white ornamental kale, and beet (Kim et al., 2014b). Growth promoting and antioxidant activities of Chlorella sp. for soybean sprouts have also been reported (Kim et al., 2015).

Recently, we have used C. fusca as a bio-fungicide. On cucumber plants, pre-treatment with suspension of C. fusca could reduce anthracnose disease severity. Appressorium formation of $C$. orbiculare on cucumber plants was apparently suppressed compared to that on untreated control (Lee et al., 2016). Furthermore, scanning electron microscopic images of leaves of algae pre-treated plants revealed that most anthracnose conidia of $C$. orbiculare were attached 
with lots of $C$. fusca cells without forming appressorium (Lee et al., 2017). These results suggest that suppression of appressorium formation by pre-treatment with $C$. fusca might play an important role in reducing anthracnose disease severity. On the other hand, the growth of cucumber plants soil-drenched with algae was apparently enhanced (unpublished data), suggesting that $C$. fusca might have biological action similar to plant-growth promoting rhizobacteria (PGPR).

Molecular mechanisms involved in systemic acquired resistance of plants may vary depending on resistanceinducing agent. Normally, pathogenesis related proteins (PR-protein) are accumulated in plants expressing systemic acquired resistance (SAR) mediated by pathogen or chemicals (Sticher et al., 1997). However, in plants expressing induced systemic resistance (ISR) by PGPR, inducible accumulation of PR-proteins is not always detected (Van Loon et al., 1998). Furthermore, SAR inducing agent does not have antifungal activity whereas PGPR has potential antifungal effect (Van Loon et al., 1998). Indeed, cytological observation has shown different infection behaviors between leaves of cucumber plants expressing SAR and ISR (Jeun et al., 2007).

However, cytological mechanism of systemic resistance medicated by C. fusca in plant tissue has not been reported yet. Therefore, the objective of this study was to illustrate the defense mechanism mediated by $C$. fusca using a transmission electron microscope (TEM) after inoculation with the anthracnose pathogen.

\section{Materials and Methods}

Plant growth. Cucumber seeds (Cucumis sativus L. cv. Jungsunsamcheok) were sown in plastic pots $(\varnothing 8 \mathrm{~cm})$ filled with a commercial soil (Number-One ${ }^{\circledR}$, Hongsung, Korea) for a week. A cucumber seedling was transplanted into a same size pot with the same soil but added with $10 \%$ of Perlite (Parat ${ }^{\circledR}$, Sam Son, Seoul, Korea). Cucumber plants were fertilized with a commercial fertilizer (PolyFeed $^{\circledR}$, Paju, Korea) every week. They were grown in a cultivating chamber with $60 \%$ relative humidity at $28^{\circ} \mathrm{C}$ during day and $3^{\circ} \mathrm{C}$ lower during night for two weeks. Two-leaf-stage plants were used for spray inoculation with C. fusca.

Cultivation of $C$. fusca and spray to cucumber plants. Green algae $C$. fusca CHK0059 was obtained from Rural Development Administration, Wanju, Korea. It was cultivated on blue-green 11 modified medium (BGMM, Kim et al., 2014a). To prepare algae suspension, a colony of $C$. fusca was inoculated in a BGMM liquid medium equipped with an air generation (PD-40, Chuangxing Electrical Appliances. Co. Ltd., Zhongshan, China) at $28^{\circ} \mathrm{C}$ under 5,000 Lux for 7 days. The concentration of algae suspension was adjusted to $2.0 \times 10^{7}$ cells $/ \mathrm{ml}$ using a hemocytometer (Hausser Scientific Inc., PA, USA).

To trigger systemic resistance, the first leaf of cucumber plants was sprayed with algae suspension added with $0.01 \%$ Tween 20 . As a positive control, $10 \mathrm{~mm}$ of DL3-aminobutyric acid (BABA) solution was used to treat plants with the same method. This concentration of BABA could successfully trigger systemic resistance against anthracnose in cucumber plants (Jeun et al., 2007). Instead of algae suspension, $\mathrm{H}_{2} \mathrm{O}$ was sprayed as a mock control. All treated plants were kept at room temperature for $3 \mathrm{~h}$ until leaves were entirely dried.

Inoculation with fungal pathogen. Colletotrichum orbiculae KACC 40808 was obtained from Korean Agricultural Culture Collection (KACC). It was used as a fungal pathogen. This anthracnose pathogen was cultivated on potato dextrose agar (PDA) at $25^{\circ} \mathrm{C}$ in the dark. To prepare conidial suspension, a piece of mycelium was inoculated onto green bean agar (Jeun et al., 2004) and incubated under a fluorescent lamp at $25^{\circ} \mathrm{C}$ for 10 days. Conidia were harvested with $10 \mathrm{ml}$ sterilized water and the concentration was adjusted to $2.5 \times 10^{5}$ conidia $/ \mathrm{ml}$. To enhance conidial adhesion to leaf surfaces, $100 \mu 1 / 1$ of Tween 20 was added to the conidial suspension.

For inoculation with fungal pathogen, second leaves were detached from cucumber plants pre-treated with $C$. fusca CHK0059, BABA, or mock control at 5 days after algae treatment. These detached second leaves were laid in Petri dishes $(\varnothing 15 \mathrm{~cm})$ maintaining 100\% humidity. Then $20 \mu \mathrm{l}$ of conidial suspension was dropped at four points on leaf surfaces. These inoculated leaves were kept at $25^{\circ} \mathrm{C}$ in the dark for 6 days. Three independent experiments were carried out in which five plants were replicated for each treatment.

Assessment of disease severity and data analysis. Disease severity was assessed based on lesion numbers: $0=$ no lesion, $1=$ lesion is visible, $2=$ lesion is discolored and become yellow, 3 = middle of lesion become gray and diameter of lesion reached $5 \mathrm{~mm}$, and $4=$ lesion is well extended and diameter of lesion reached $10 \mathrm{~mm}$. Levels of disease severity were statistically analyzed using Duncan's multiple range tests (DMRT). Statistical analysis of experimental data was conducted using Statistical Analysis System (SAS institute, version 9.0). 
Preparation for transmission electron microscope. Leaf tissue containing a necrotic lesion was cut using a razor blade to size of $1 \times 3 \mathrm{~mm}^{3}$ at three days after inoculation. Nine leaf tissues for every treatment were prepared from cucumber plants pre-treated with C. fusca CHK0059, BABA, or mock. Fixation, dehydration, and embedding of leaf tissues were carried out as described previously by Hayat (1989). Pre-fixation was carried out in modified Karnovsky's fixative ( $2 \%$ paraformaldehyde and $2 \%$ glutaraldehyde in $0.05 \mathrm{M}$ sodium cacodylate buffer, $\mathrm{pH} 7.2$ ) at $4^{\circ} \mathrm{C}$ for 2-4 h. After washing with $0.05 \mathrm{~m}$ sodium cacodylate buffer ( $\mathrm{pH}$ 7.2) three times, post-fixation was performed with $1 \%(\mathrm{w} / \mathrm{v})$ osmium tetroxide in the same buffer at $4^{\circ} \mathrm{C}$ for $2 \mathrm{~h}$ and briefly washed with distilled water at room temperature twice. These leaf tissues were dehydrated through an alcohol series soaking in 30,50, 70, 90, and 100\% alcohol twice (each for $30 \mathrm{~min}$ ), respectively. Alcohol in the sample was exchanged with an epoxy resin (vinylcyclohexene dioxide, ERL 4206) (Spurr, 1969) followed by polymerization at $70^{\circ} \mathrm{C}$ for $8 \mathrm{~h}$.

Embedded blocks were ultra-thin sectioned with thickness of $60 \mathrm{~nm}$ using an ultramicrotome (MT-X, RMC, Tucson, AZ, USA). These sections were mounted on copper grids, were stained with $2 \%(\mathrm{w} / \mathrm{v})$ uranyl acetate in $\mathrm{H}_{2} \mathrm{O}$ for $10 \mathrm{~min}$, and lead citrate manufactured according to Reynolds (1963) for $2 \mathrm{~min}$. Ultra-structures of fungal pathogen behavior in plant cells were examined using a transmission electron microscope (JEM-1011, JEOL, Tokyo, Japan) at $80 \mathrm{kV}$.
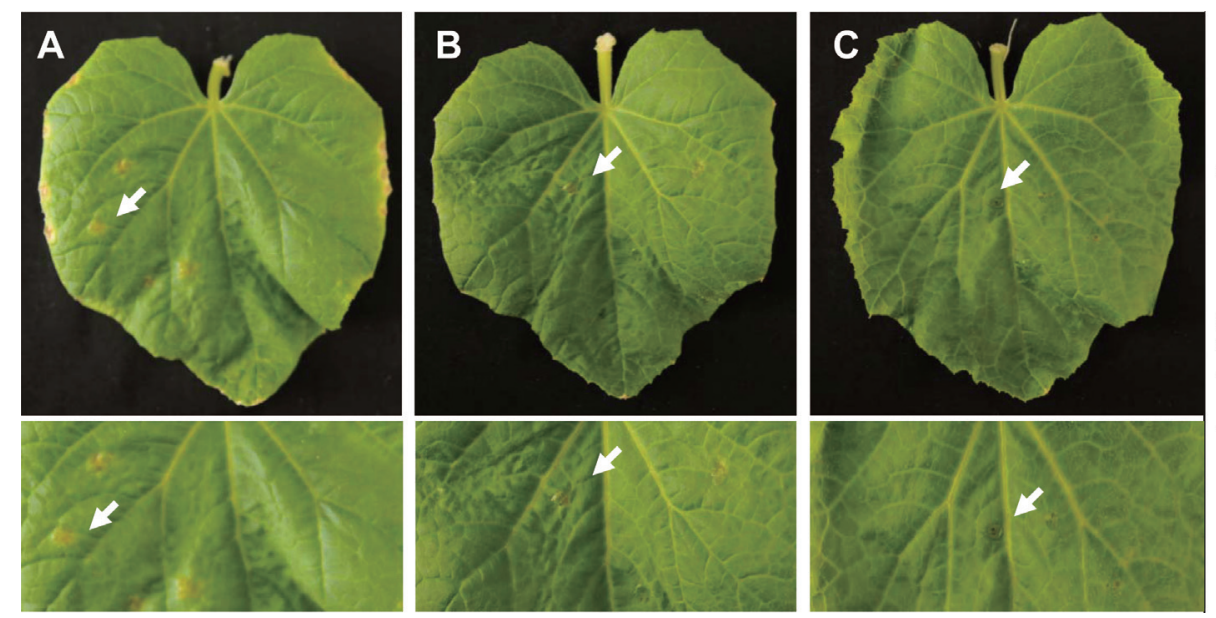

Image processing. TEM images were transferred by Gatan Digital Micrograph (Gatan Erlangshen 785 ES1000W, GATAN, CA, USA). Data were transferred to a computer and images were printed using a photographic-grade printer (Pictrography 3000, TX, USA).

\section{Results}

SAR-expressing leaves mediated by $C$. fusca. After inoculation with $C$. orbiculare, typical anthracnose lesions were formed on leaves of untreated cucumber plants. At 6 days after fungal inoculation, anthracnose lesions were apparently visible on leaves (Fig. 1A). The size of lesions was rapidly increased, indicating that fungal hyphae extended further in the host tissue as time went by.

On leaves of plants pre-sprayed with $C$. fusca, anthracnose lesions appeared later compared to untreated one. These lesions did not appear to be increased by time, unlike untreated plants (Fig. 1B). Small lesions were observed in most SAR expressing leaves mediated by $C$. fusca. Limited lesion indicated that anthracnose pathogen could not well extend in SAR-expressing leaves.

Similarly, the severity of anthracnose was reduced on leaves pre-treated with BABA, a well-known resistance induction agent (Cohen, 2002). Lesions were too small to be identified at the inoculation site by fungal pathogen (Fig. 1C). Leaves expressing SAR induced by BABA indicated that the process of SAR induction mediated by $C$. fusca was involved in this study.

Fig. 1. Anthracnose lesions on second leaves of cucumber plants in untreated (A), pre-sprayed with C. fusca (B), and pre-treated with BABA (C) on first leaves. The level of disease severity on cucumber plants untreated or pre-sprayed with $C$. fusca and BABA (D). The criterion of disease severity level was described in 'Materials and Methods'. Vertical bars indicate standard deviation of three separated experiments containing five replications each. Different letters on the columns indicate significant differences $(P<0.05)$ according to Duncan's multiple test. Concentrations of algae and BABA were $2.0 \times 10^{7}$ conidia $/ \mathrm{ml}$ and $10 \mathrm{~mm}$, respectively. These photographs were taken at 6 days after inoculated with the suspension of $C$. orbiculare at concentration with $1.0 \times 10^{5}$ conidia/ml on second leaves. Magnified images are lesions indicated by arrow on photographs shown above. 
From three separated experiments, it was revealed that disease severity could be reduced by treatment with $C$. fusca suspension. Such suppression efficacy by the algae was similar to that mediated by BABA, one effective SAR trigger agent (Fig. 1D).

Infection behavior of $C$. orbiculare in untreated plants. Ultrastructures of $C$. orbiculare in untreated plants were examined by TEM at different time points after inoculation. In order to illustrate host-parasite interaction, intracellular hyphae were predominantly observed. At 3 days after inoculation, both biotrophic and necrotrophic phases were observed in the invading fungi. In the biotrophic phase, most organelles of host cell such as chloroplast were found to be intact (Fig. 2A). In this phase, plant cells began to react against fungal invasion, resulting in accumulation of vesicles in neighbor mesophyll cells (Fig. 2B arrow). However, such reaction appeared to be insufficient to deter hyphal invasion.

In necrotrophic phases, either destroy of tonoplast (Fig. $2 \mathrm{C}$ arrow) or denature of cell organelles was observed (Fig. 2D arrow) while cell structures of anthracnose fungi were unchanged. Furthermore, electron densities of most intracellular hyphae were similar compared to those of the organelles of plant cells (Fig. 2B-2D) indicating a compatible interaction between the host cell and the parasite.

Defense responses of plants pre-spayed with $C$. fusca. Ultrastructures of infection sites in SAR-expressing leaves mediated by $C$. fusca were different to those found in leaves of untreated plants. In biotrophic phase, numbers of vesicles (Fig. 3A arrow) were observed around intracellular hyphae and electron densities were higher in the cytoplasm compared to those in untreated leaves (Fig. 3A). When fungal hyphae invaded neighboring host cells, cytoplasmic sheaths containing spherical vesicles were often formed
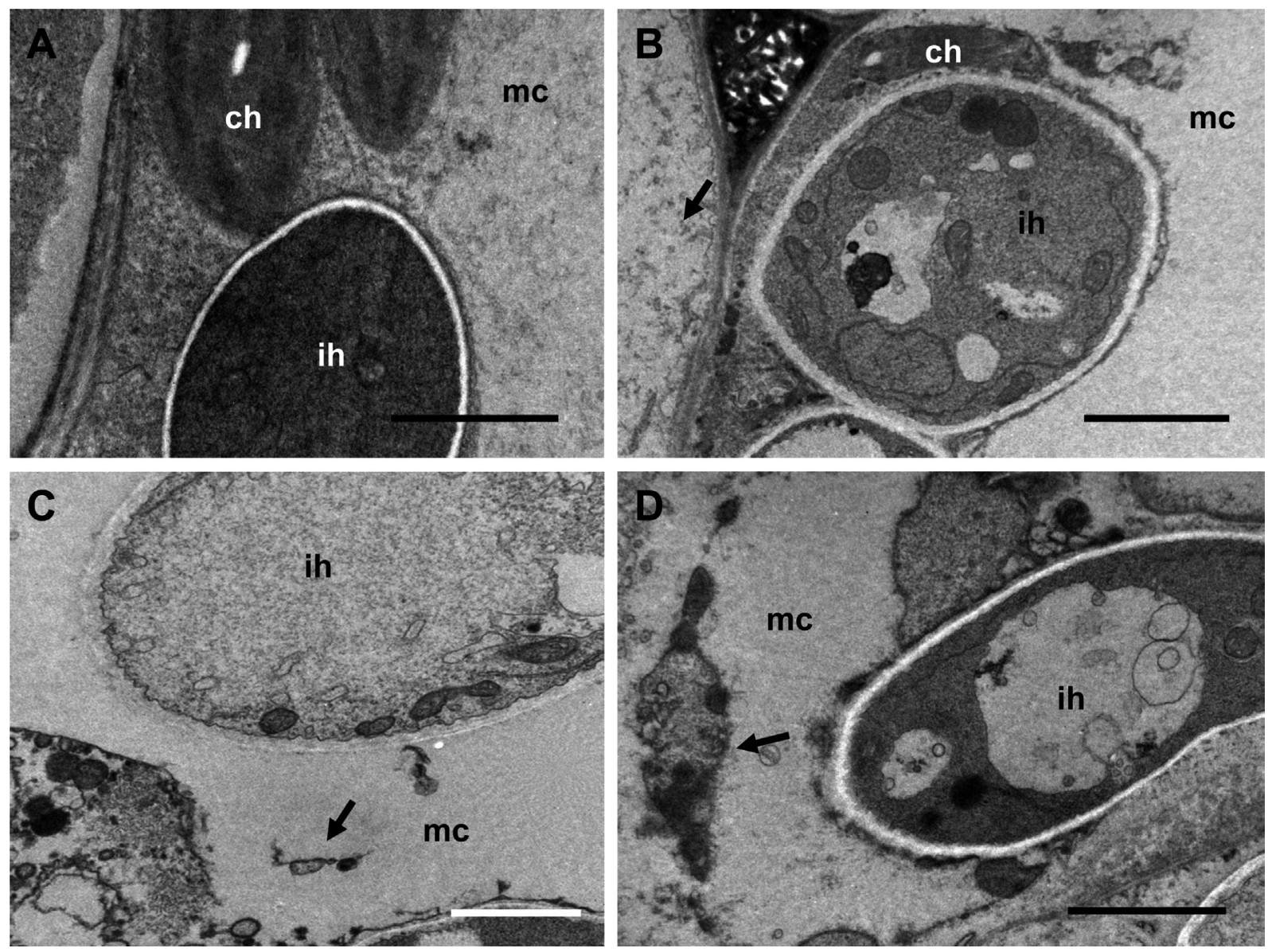

Fig. 2. Transmission electron micrographs in leaves of untreated cucumber plants at 3 days after inoculation with $C$. orbiculare. (A) Intracellular hyphae at the biotrophic phase without evidence of a defense reaction. (B) Some vesicles (arrow) in neighbor cells not enough to express resistance. (C) Intracellular hyphae at necrotrophic phase with broken down of tonoplast (arrow). (D) Collapsed cytoplasm (arrow) showing no active defense reaction around intracellular hyphae. The concentration of C. orbiculare was $1.0 \times 10^{5}$ conidia/ml. All bars $=2 \mu \mathrm{m}$. Abbreviation: ch, chloroplast; ih, intracellular hyphae; mc, mesophyll cell. 

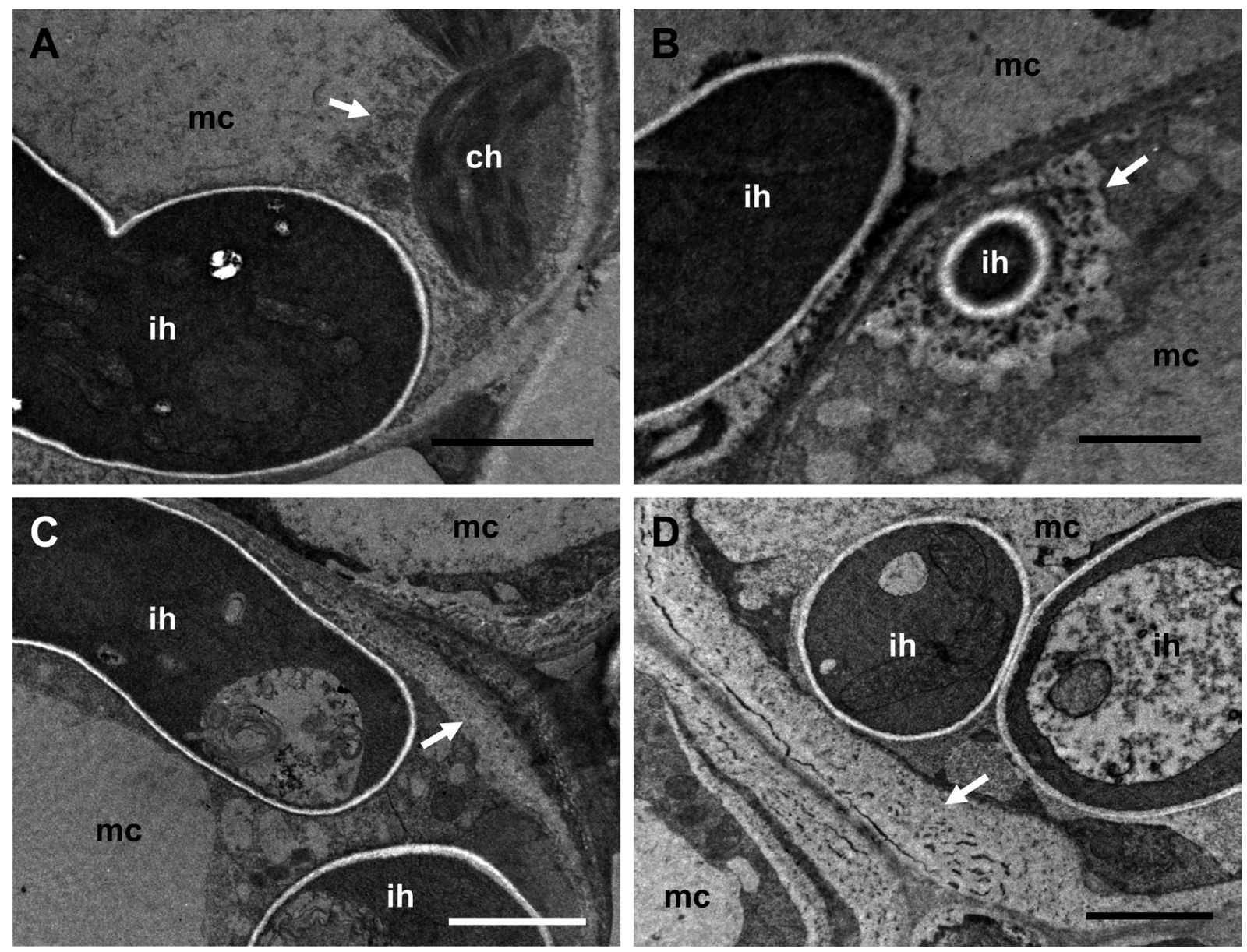

Fig. 3. Transmission electron micrographs of leaves of cucumber plants pre-sprayed with C. fusca and post inoculated with C. orbiculare five days later. (A) Electron dense intracellular hyphae at biotrophic phase with active defense reaction such as accumulation numbers of vesicles (arrow). (B) Electron dense intercellular hyphae and cytoplasmic sheath (arrow) around intracellular hyphae in the neighbor mesophyll cell. (C) Electron dense intracellular hyphae adjoining a thickened host cell well (arrow). (D) Separated from the host cell wall and generated a space (arrow) in necrotrophic phase. Concentrations of C. fusca and C. orbiculare were $2.0 \times 10^{7}$ cells $/ \mathrm{ml}$ and $1.0 \times 10^{5}$ conidia/ml, respectively. All bars $=2 \mu \mathrm{m}$. Abbreviation: ch, chloroplast; ih, intracellular hyphae; is, intercellular space; mc, mesophyll cell.

around the penetration hyphae (Fig. 3B arrow) which might suppress the extension of fungal pathogen into host tissues. Host cell walls adjoining with the intracellular hyphae were also thickened (Fig. 3C arrow), indicating a defense mechanism activated by pre-spayed $C$. fusca. Thickening of host cell well is typically found in an incompatible interaction between host and pathogen. Furthermore, in some cases, plasma membrane was separated from host cell well, generating a space adjoin of intracellular hyphae in which numerous small tubules were found (Fig. 3D arrow). Such morphological changes were not detected in untreated plants. This might be due to incompatible reactions between host and pathogen.

Defense responses of cucumber plants pre-treated with BABA. Intracellular hyphae were rarely found in BABA pre-treated plants tissues after challenge inoculation. Most infection sites observed in BABA pre-treated plants showed incompatible interactions between host and pathogen, similar to those observed in algae pre-sprayed plants. Like algae pre-sprayed plants, host cell thickness was observed in the infection site of BABA pre-treated plants (Fig. 4A arrow). Electron densities of intercellular hyphae of BABA pre-treated plants were also higher than those of untreated plants (Fig. 4A). Numerous mitochondria were accumulated in the parenchyma host cell, indicating an active defense response (Fig. 4B arrow, 4D). Around intracellular hyphae, vesicles were observed (Fig. 4C, 4D arrow). They were also observed in algae pre-sprayed plants (Fig. 3A arrow). This showed that the mechanism of SAR expressing host cells was similar between algae pre-spayed and BABA pre-treated plants. 

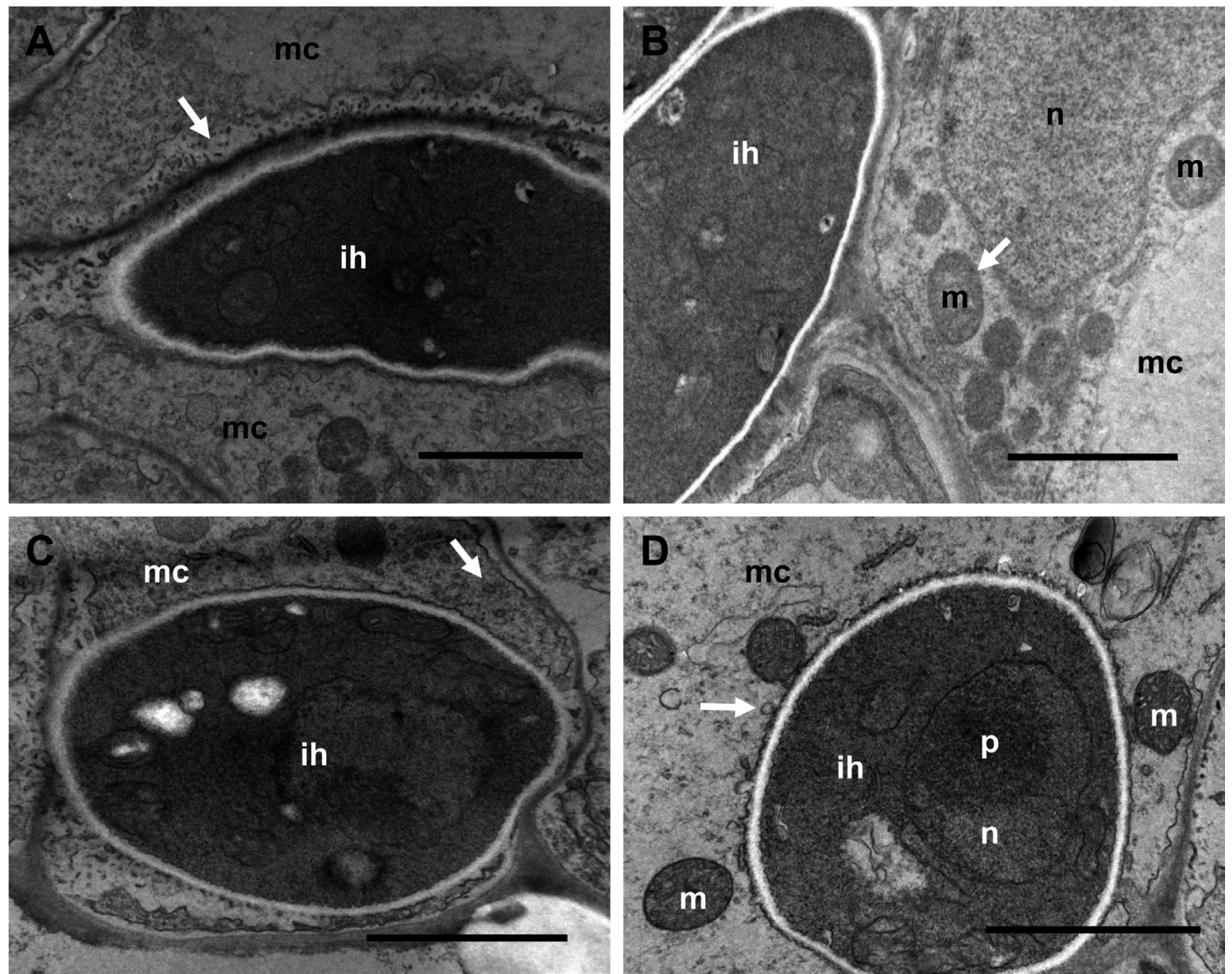

Fig. 4. Transmission electron micrographs in leaves of cucumber plants pre-treated with DL-3-Amino butyric acid (BABA) and post inoculated with $C$. orbiculare five days later. (A) Electron dense intracellular hyphae with host cell wall thickness (arrow). (B) Intracellular hyphae in neighbor host cell with numerous mitochondria (arrow). (C, D) Electron dense intracellular hyphae with numbers of vesicles (arrows). Concentrations of BABA and C. orbiculare were $10 \mathrm{~mm}$ and $1.0 \times 10^{5}$ conidia $/ \mathrm{ml}$, respectively. All bars $=2 \mu \mathrm{m}$. Abbreviation: ih, intracellular hyphae; m, mitochondria; mc, mesophyll cell; $n$, nucleus; $p$, nucleolus.

\section{Discussion}

SAR is normally mediated by environmental stimuli such as pathogen and chemicals (Sticher et al., 1997). In some cases, resistance is also induced by plant growth rhizobacteria (PGPR) which has been defined as induced systemic resistance (Van Loon et al., 1998). In the last two decades, both SAR and ISR have been continuously investigated in many crops (Gozzo and Faoro, 2013; Sarma et al., 2015). However, systemic resistance mediated by algae has been rarely reported. This study clearly revealed that green algae C. fusca could trigger systemic resistance against cucumber anthracnose (Fig. 1). Systemic resistance mediated by a microorganism, including algae, is expected to be expressed on leaf surfaces by callose formation at the penetration sites
(Jeun et al., 2000). Systemic resistance in plant cells induced by priming can result in some biochemical changes, including the production of anti-fungal substance phytoalexin (Siegrist et al., 2000), the accumulation of PR-proteins (Jeun, 2000), and the production of enzymes involved in the metabolism of reactive oxygen species (Lamb and Dixon, 1997). In order to illustrate the resistance mechanism in host tissues pre-sprayed with this algae, cytological infection structures were observed using a TEM.

It is known that anthracnose pathogen has two steps of nutrition uptake in their infection processes. After penetration of the pathogen into host cell, biotrophic interactions will take place in the presence of primary hyphae. The second step appears as necrotrophic interactions with secondary hyphae (Bailey et al., 1992). In this study, at one day after inoculation, fungal hyphae stayed at biotrophic 
phase were very rarely found (data not shown). At 5 days after inoculation, either biotrophic or necrotrophic phases was hardly found due to severe collapse of cell structures at the infection site (data not shown). Therefore, in this study, images were mostly observed at 3 days after inoculation. Typical infection behaviors of anthracnose pathogen were observed in untreated cucumber leaves at 3 days after inoculation (Fig. 2), similar to those of untreated cucumber plants shown in our previous study (Jeun et al., 2007).

In leaves of algae pre-spayed plants, both biotrophic and necrotrophic phases were observed. However, dissimilarly with untreated plants, active defense responses of host cells were frequently observed in C. fusca pre-sprayed plants including accumulation of vesicles, formation of sheath around penetration hyphae, and thickness of cell wells adjoining with intracellular hyphae (Fig. 3). These cytological changes may cause suppression of hyphal growth of anthracnose pathogen in host tissues. Furthermore, electron densities of most intracellular hyphae found in algae presprayed plants were higher than those in untreated ones (Fig. 2, 3). Similar mechanical defense responses and high electron density in intracellular hyphae have also been observed in typical ISR expressing cucumber leaves mediated by PGPRs (Jeun et al., 2007) or in SAR expressing tomato leaves infected by Tobacco necrosis virus (Jeun and $\mathrm{Bu}-$ chenauer, 2001). These observations suggest that resistance mechanisms mediated by $C$. fusca might be similar to those in SAR or ISR expressing plants.

In BABA pre-treated plants, typical resistant reactions found in SAR expressing cells were observed in this study (Fig. 4). Similar defense responses in algae pre-sprayed plants such as accumulation of vesicles and mitochondria at infection sites indicated that fungal hyphae could not well extend into the host mesophyll cell (Fig. 3, 4). Intracellular hyphae were also electron dense (Fig. 4), similar to those observed in our previous study (Jeun et al., 2007). These observations indicate that mechanical resistance reactions mediated by $C$. fusca might be similar to those induced by chemical BABA in cucumber plants. Defense responses of host cells in BABA pre-treated plants were not often observed in our previous study. It appeared that TEM images were not enough to find defense responses because hyphae were rarely found at that time (Jeun et al., 2007).

On the other hand, decreased disease severity by algae might be caused by mechanical defenses and biochemical activation. In bean plants expressing ISR, amounts of phenolic compounds or lignin have been found to be increased (Martins et al., 2013). Amounts of peroxidase, $\beta$-1,3-glucanase, and chitinase are also greatly increased in rice pre-treated with a rhizobacterial isolate (Filippi et al.,
2011). In Arabidopsis thaliana, the expression of phytoalexin producing gene is elevated after colonization with a hypovirulent Rhizoctonia isolate which is a biological control agent (Sharon et al., 2011). These biochemical defense responses might play a role in resistance expression in leaves of cucumber plants pre-sprayed with $C$. fusca. More investigation concerning the biochemical resistant mechanism mediated by algae is required.

In summary, defense responses of mesophyll cell in systemic resistance expressing cucumber plants medicated by $C$. fusca were cytologically similar to those in SAR expressing plants induced by BABA. These observations suggest that green algae $C$. fusca may play a role as a biological agent which could mediate SAR or ISR. To illustrate SAR mediated by $C$. fusca more clearly, further molecular studies such as changes in SAR-specific gene expressions are needed.

\section{Acknowledgments}

We thank Dr. Sim C. K., Organic Agriculture Division, National Academy of Agricultural Science, Rural Development Administration, Wanju 54875, Korea for supplying Chlorella fusca CHK0059 strain and Korean Agricultural Culture Collection (KACC) for providing anthracnose pathogen Colletotrichum orbiculae KACC 40808. This work was supported by the research grant of Jeju National University in 2015.

\section{References}

Arita, C. E. Q., Peebles, C. and Bradley, T. H. 2015. Scalability of combining microalgae-based biofuels with wastewater facilities: a review. Algal Res. 9:160-169.

Bailey, J. A., O’Connell, R. J., Pring, R. J. and Nash, C. 1992. Infection strategies of Colletotrichum species. In: Colletotrichum: biology, pathology and control, eds. by J. A. Bailey and M. J. Jeger, pp. 88-120. CAB International, Wallingford, UK.

Bhatt, N. C., Panwar, A., Bisht, T. S. and Tamta, S. 2014. Coupling of algal biofuel production with wastewater. Sci. World J. 2014:210504.

Cohen, Y. R. 2002. $\beta$-aminobutyric acid-induced resistance against plant pathogens. Plant Dis. 86:448-457.

Chiu, S. Y., Kao, C. Y., Chen, T. Y., Chang, Y. B., Kuo, C. M. and Lin, C. S. 2015. Cultivation of microalgal Chlorella for biomass and lipid production using wastewater as nutrient resource. Bioresour. Technol. 184:179-189.

Filippi, M. C. C., Barata da Silva, G., Silva-Lobo, V. L., Cortes, M. V. C. B., Moraes, A. J. G. and Prabhu, A. S. 2011. Leaf blast (Magnaporthe oryzae) suppression and growth promotion by rhizobacteria on aerobic rice in Brazil. Biol. Control. 58:160- 
166.

Gozzo, F. and Faoro, F. 2013. Systemic acquired resistance (50 years after discovery): moving from the lab to the field. $J$. $A g$ ric. Food Chem. 61:12473-12491.

Hayat, M. A. 1989. Principles and techniques of electron microscopy: biological applications. 3rd ed. The Macmillan Press LTD.

Jeun, Y. C. and Buchenauer, H. 2001. Infection structures and localization of the pathogenesis-related protein AP24 in leaves of tomato plants exhibiting systemic acquired resistance against Phytophthora infestans after pre-treatment with 3 -aminobutyric acid or tobacco necrosis virus. J. Phytopathol. 149:141-153.

Jeun, Y. C., Kim, K. W., Kim, K. D. and Hyun, J. W. 2007. Comparative ultrastructure of cucumbers pre-treated with plant growth-promoting rhizobacteria, DL-3-aminobutyric acid or amino salicylic acid after inoculation with Colletotrichum orbiculare. J. Phytopathol. 155:416-425.

Jeun, Y. C., Park, K. S., Kim, C. H., Fowler, W. D. and Kloepper, J. W. 2004. Cytological observations of cucumber plants during induced resistance elicited by rhizobacteria. Biol. Control. 29:34-42.

Jeun, Y. C. 2000. Immunolocalization of PR-protein P14 in leaves of tomato plants exhibiting systemic acquired resistance against Phytophthora infestans induced by pretreatment with 3-aminobutyric acid and preinoculation with Tobacco necrosis virus. J. Plant Dis. Protect. 107:352-367.

Jeun, Y. C., Sigrist, J. and Buchenauer, H. 2000. Biochemical and cytological studies on mechanisms of systemically induced resistance in tomato plants against Phytophthora infestans. J. Phytopathol. 148:129-140.

Kim, M. J., Shim, C. K., Kim, Y. K., Hong, S. J., Park, J. H., Han, E. J., Jee, H. J., Lee, S. B. and Kim, S. C. 2015. Effect of Chlorella sp. on improving antioxidant activities and growth promotion in organic soybean sprout cultivation. Korean J. Org. Agric. 23:939-950.

Kim, M. J., Shim, C. K., Kim, Y. K., Hong, S. J., Park, J. H., Han, E. J., Jee, H. J., Yun, J. C. and Kim, S. C. 2014a. Isolation and morphological identification of fresh water green algae from organic farming habitats in Korea. Korean J. Org. Agric. 22:743-760.

Kim, M. J., Shim, C. K., Kim, Y. K., Park, J. H., Hong, S. J., Ji, H.
J., Han, E. J. and Yoon, J. C. 2014b. Effect of Chlorella vulgaris CHK0008 fertilization on enhancement of storage and freshness in organic strawberry and leaf vegetables. Korean $J$. Hortic. Sci. Technol. 32:872-878 (in Korean).

Lamb, C. and Dixon, R. A. 1997. The oxidative burst in plant disease resistance. Annu. Rev. Plant Physiol. Plant Mol. Biol. 48:251-275.

Lee, Y. J., Ko, Y. J. and Jeun, Y. C. 2016. Illustration of disease suppression of anthracnose on cucumber leaves by treatment with Chlorella fusca. Res. Plant Dis. 22:257-263 (in Korean).

Lee, Y. J., Kim, S. J. and Jeun, Y. C. 2017. Ultra-structural observations of Colletotrichum orbiculare on cucumber leaves pre-treated with Chlorella fusca. Res. Plant Dis. 23:42-48 (in Korean).

Martins, S. J., Vasconcelos de Medeiros, F. H., Magela de Souza, R., Vilela de Resende, M. L. and Ribeiro Junior, P. M. 2013. Biological control of bacterial wilt of common bean by plant growth-promoting rhizobacteria. Biol. Control. 66:65-71.

Matusiak, K. and Krzywicka, A. 1975. Influence of the extract of Chlorella vulgaris on growth of fungi. Acta. Microbiol. Pol. Ser. B 7:51-54.

Reynolds, E. S. 1963. The use of lead citrate at high $\mathrm{pH}$ as an electron opaque stain in electron microscopy. J. Cell Biol. 17:208.

Sarma, B. K., Yadav, S. K., Singh, S. and Singh, H. B. 2015. Microbial consortium-mediated plant defense against phytopathogens: Readdressing for enhancing efficacy. Soil Biol. Biochem. 87:25-33.

Sharon, M., Freeman, S. and Sneh, B. 2011. Assessment of resistance pathways induced in Arabidopsis thaliana by hypovirulent Rhizoctonia spp. isolates. Phytopathology. 101:828-838.

Siegrist, J., Orober, M. and Buchenauer, H. 2000. Beta-aminobutyric acid-mediated enhancement of resistance in tobacco to tobacco mosaic virus depends on the accumulation of salicylic acid. Physiol. Mol. Plant Pathol. 56:95-106.

Spurr, A. R. 1969. A low-viscosity epoxy resin embedding medium for electron microscopy. J. Ultrastruct. Res. 26:31.

Sticher, L., Mauch-Mani, B. and Métraux, J. P. 1997. Systemic acquired resistance. Annu. Rev. Phytopathol. 35:235-270.

Van Loon, L. C., Bakker, P. A. H. M. and Pieterse, C. M. J. 1998. Systemic resistance induced by rhizosphere bacteria. Annu. Rev. Phytopathol. 36:453-483. 